2 Asthana A, Mason R. UK must leave European convention on human rights, says Theresa May. The Guardian, 2016; 25 April (https://www. theguardian.com/politics/2016/apr/25/uk-must-leave-europeanconvention-on-human-rights-theresa-may-eu-referendum).

3 Moohan and another $v$ Lord Advocate [2014] UKSC 67 (https://www supremecourt.uk/decided-cases/docs/UKSC_2014_0183_Judgment.pdf).

doi: $10.1192 / \mathrm{pb} \cdot 40.6 .347 \mathrm{a}$

\section{Liaison psychiatry: a brief history}

Aitken et al suggest that it was the bringing together of the alienists (asylum doctors) and academics that 'enabled' liaison psychiatry to be recognised as a subspecialty by the newly founded Royal College of Psychiatrists. ${ }^{1}$ However, I would argue that change in the practice of psychiatry prior to that date was much more determined by the Report of the Royal Commission on the Law Relating to Mental IIIness and Mental Deficiency ${ }^{2}$ that led to the 1957 Mental Health Act. Foremost among its recommendations were:

(1) to place mental illness and mental deficiency on the same footing as other illnesses or disabilities

(2) to abolish special designation of psychiatric hospitals

(3) to expand community services.

Subsequently, W. S. Maclay gave an academic address to the 1st Canadian Mental Hospitals Institute entitled Experiments in Mental Hospital Organisation, in which he outlined the likely future progression of these recommendations based on developments in the Manchester region. As early as 1948 the medical administrative staff of the Manchester Regional Hospital Board had begun to address how best to serve the care of psychiatric patients. It was agreed that psychiatric care should be as far as possible analogous to that of all healthcare - community facilities together with primary medical services, and secondary medical provision within local general hospitals. Psychiatric units of 100 to 200 beds were developed within district general hospitals (DGHs) and a consultant psychiatrist and support staff appointed to each unit from 1954.

Initially, there was little or no support from the large hospitals or academic psychiatric departments of the region. However, the regional clinical research committee requested a review of such units in 1960. This was carried out by Dr Stanley Smith, the superintendent of a large mental hospital. It is worth quoting the final paragraph of his 'Review of Psychiatric Units Associated with General Hospitals in the Area of the Manchester Regional Hospital Board':

'In my view they (these units) may well be the most significant social development in British psychiatry today'.

The existing DGHs of the Manchester region were based on the needs of individual communities ('ecologies'). They were built physically and conceptually from the provision made available by central and regional health services, local government and the community and charitable resources of each area. 'Liaison' was implicit to successful provision of overarching healthcare in such facilities.

Services continued to evolve in the DGH psychiatric unit in which I had my longest experience - and which served 200000 people. These included in-patient beds for people with acute illness, those with chronic illness and elderly patients. A number of beds on the general wards were assigned to psychiatry; they were used for investigation of mental illness and for drug withdrawal. Additionally, beds were held on medical wards for the direct admission of patients who had attempted suicide by drug overdose - these were seen by consultant psychiatrists and social workers before discharge. The average duration of stay of all in-patients was 3 to 4 weeks throughout those 30 years.

Progress in modes of psychiatric treatment was readily acknowledged by the hospital management. The advent of behaviour therapy led to the establishment of a clinical psychology department in 1966 - probably the first of its kind in a DGH. Psychiatric social workers were attached to each consultant team. The laboratory biochemical facilities were extended to allow monitoring of drug therapy and substance misuse.

Before the formal role of community psychiatric nurse was established, nurses from the hospital used to visit patients in their homes if this was felt appropriate. Readily available links to psychiatric assessment were made with the police, the large local Salvation Army hostel and local organisations that dealt with homelessness. A drug team was jointly established with the local authority. An industrial unit served those with work maladjustment. An Alcoholics Anonymous group held its meeting within the hospital. There was a well-recognised postgraduate teaching centre within the DGH which organised regular seminars that included psychiatric topics.

Consultant numbers grew from one to four, enabling a duty consultant to cover intra-hospital consultations and outof-hours emergency calls from whatever source, in addition to requests from primary care and community organisations. All waiting list referrals were seen within 4 weeks. All the intervention categories that Aitken et al describe were part and parcel of the service.

Guthrie et al commented that one of the most difficult aspects of any provision is that of measuring outcomes. ${ }^{3}$ The DGH model aimed to give 'comprehensive' healthcare to a district, defined as the smallest population for which such healthcare could be satisfactorily planned, organised and provided. This required the greatest possible co-ordination between health services and the local authority, particularly social services. The majority of districts were expected to serve a population of less than 250000 .

Owing to the closed population and ready liaison with groups and individuals, outcomes could easily be measured. Follow-up clinics, re-referrals and community responses, together with statutory and non-statutory data collection, ensured awareness of changing needs. The importance of early clinical intervention and continuity of care became apparent and data were used to sustain appropriate staffing, bed numbers and budgeting in the DGH.

Lastly, it is my personal view that the Mental Health Act 1983 and the establishment of mental health trusts have hugely emphasised the dichotomy between mental and physical healthcare. I believe that liaison - intimate communication - with both the individual and his or her 'ecosystem' is necessary to all good quality care and cannot be prescribed. It is not particular to psychiatric practice; it is the hallmark of good doctoring in all specialties.

John T. Elliott, Retired Consultant Psychiatrist, UK; email: jjtelliott@aol.com

1 Aitken P, Lloyd G, Mayou R, Bass C, Sharpe M. A history of liaison psychiatry in the UK. BJPsych Bull 2016; 40: 199-203. 
2 HM Government. Report of the Royal Commission on the Law Relating to Mental IIIness and Mental Deficiency 1954-1957 (Cmnd 169). HMSO, 1957.

3 Guthrie E, McMeekin A, Thomasson R, Khan S, Makin S, Shaw B, et al. Opening the 'black box': liaison psychiatry services and what they actually do. BJPsych Bull 2016; 40: 175-80.

doi: $10.1192 / \mathrm{pb} .40 .6 .348$

\section{Psychiatrists' use of psychological formulation}

In a qualitative study ${ }^{1}$ Mohtashemi et al have helpfully explored the use of psychological formulation by adult psychiatrists. They describe how this is limited in extent and discuss the implications of these findings from the perspective of clinical psychologists. We would like to offer some additional observations from a different perspective, that of psychiatrists with a particular interest in the use of formulation in everyday psychiatric practice.

It is perhaps worth mentioning that the term 'formulation' continues to be used in different ways, as it has been for at least 30 years. ${ }^{2,3}$ Sometimes it denotes a summing up of a case and its management, sometimes an interpretation of why a problem is occurring.

We suggest that many psychiatrists do not share the view that the core tasks of psychiatry should be diagnosis and medication. This is not the position of the Royal College of Psychiatrists, ${ }^{4}$ and in our personal experience colleagues are frequently seeking to practise in a way which is genuinely biopsychosocial. Unfortunately, it is common for psychiatrists to report that pressures of time and the expectations of services and patients lead to diagnosis and medication dominating more than they would wish. When many psychiatrists are trying to practise holistically, we believe that the term 'medical model' as used in the paper is misleading and that the term 'biological model' perhaps more aptly describes the views which Mohtashemi et al see as conflicting with clinical psychologists' perspectives. There is a similar issue in the paper's use of the term 'psychiatric formulation', which seems again to imply something that would not include psychological elements. We strongly believe that, when well conducted, formulation by psychiatrists should always consider psychological elements and that in practice conflict between psychiatrists' and psychologists' views may be less frequent than the paper appears to imply.

While we agree with the authors that team formulation with clinical psychologists is valuable, we think that overemphasising its importance risks overlooking other ways in which formulation may be helpful. Recently, for example, increasing attention has been given to the potential of a dialogical approach, as in the open dialogue model. For clinicians seeing patients who may not go on to be supported by a multidisciplinary team, a relevant skill will be that of conducting initial assessments in such a way that consultation includes thinking collaboratively with the patient about what may be contributing to their problems and, in doing so, giving due respect to psychological and social as well as biological factors, and to the patient's perspective.

We agree that team formulation with clinical psychologists may be helpful in supporting psychiatrists to make more use of psychological formulation and we welcome the suggestion for some overlap in the training of psychologists and psychiatrists. However, we think that if psychiatrists are to make optimal use of psychological formulation, we need to do more than increase contact with clinical psychologists. Most importantly, progress is likely to be limited without attention to the systemic barriers that make it hard even for the most highly motivated psychiatrists to give adequate emphasis to psychological formulation. We believe that training should address psychiatrists' particular needs such as being able to combine understanding of both psychosocial and biological elements - and should recognise the drawbacks of an excessive focus on biological explanations. Having a genuine belief in the value of psychological formulation is likely in itself to have a significant impact on how much it is used. We think that there is scope for making better use of existing training opportunities - such as the Balint groups available in all trusts that train psychiatrists - and for making better use of the requirements for higher specialist training to include ongoing training in psychotherapeutic skills. We believe that greater emphasis on formulation skills in workplace-based assessments and examinations might make a significant difference. Beyond training, consultant Balint groups and other arrangements that support reflective practice are likely to also support development of formulation skills. Medical psychotherapists and other psychiatrists with specialist training in working psychologically are likely to be well placed to contribute to training and support for colleagues, as well as to team formulation.

The study by Mohtashemi et al seems part of a surge of interest in formulation and how it might be used more effectively. The interest has been shared by psychiatrists; the Royal College of Psychiatrists' Medical Psychotherapy Faculty and General Psychiatry Faculty executives have recently agreed good practice guidelines for the use of formulation in general psychiatric practice, and these are likely to be adopted shortly as formal College guidance (details available from the authors on request). An information leaflet for patients based on the same guidance is also being developed. An initiative aiming to enhance training in formulation across disciplines has recently been set up by Health Education England, and the multi-agency working group includes representatives of both the British Psychological Society and the Royal College of Psychiatrists.

\section{Declaration of interest}

A.S., on behalf of the Medical Psychotherapy Faculty Executive Committee, was the lead author of Using Formulation in General Psychiatric Care: Good Practice (Occasional Paper OP103, Royal College of Psychiatrists, 2017).

Alison Summers, Locum Consultant Psychiatrist, Lancashire Care NHS Foundation Trust, UK; email: alison.summers77@gmail.com, and Susan Mizen, Consultant in Medical Psychotherapy, Devon Partnership NHS Trust and Chair, Royal College of Psychiatrists Medical Psychotherapy Faculty Executive Committee

1 Mohtashemi, R, Stevens J, Jackson PG, Weatherhead S. Psychiatrists' understanding and use of psychological formulation: a qualitative exploration. BJPsych Bull 2016; 40: 212-6.

2 Hollyman JA, Hemsi L. What do psychiatrists understand by formulation? A survey of clinicians in a group of hospitals in London. Psychiatr Bull 1983; 7: 140-3.

3 Hollyman JA, Hemsi L. What do the examiners understand by formulation? A survey of the members of the College's board of examiners. Psychiatr Bull 1983; 7: 165-6.

4 Royal College of Psychiatrists (2014). When Patients Should Be Seen by a Psychiatrist (CR184). Available at http://www.rcpsych.ac.uk/ usefulresources/publications/collegereports/cr/cr184.aspx

doi: $10.1192 / \mathrm{pb} .40 .6 .349$

\section{Bulletin}

